\title{
Meeting the millennial mindset challenge
}

\section{Tracy Stuart ${ }^{1}$ considers the need to meet millennial expectations in dental practice, and that this can be achieved with flying colours when the dental team embraces a healthy mindset.}

\begin{abstract}
Author information
'Tracy Stuart is the inspiration behind NBS Training and is passionate about helping dental practice owners and their teams achieve excellence through mentoring and coaching to achieve their highest potential. Tracy's forte is escalating dental teams' effectiveness and performance through enhanced leadership and bespoke personal development. Tracy is highly sought after as a motivational speaker and as a successful Dental Business Coach \& Dental Team Trainer within the UK dental profession.
\end{abstract}

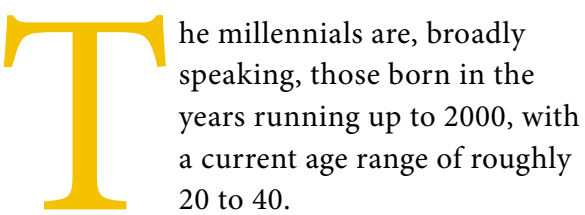

A major study by YouGov in 2019 into spending habits revealed that millennials are the most valuable consumers and represent about $35 \%$ of the global workforce. In the UK, there are around 13 million millennials, representing a fifth of the population.

There is a great opportunity here to give patients in this age group both what they need and want in terms of their oral health, and the path to success is the dental team embracing a healthy mindset - as you will see.

\section{Generation expectations}

There seems to be a general view that millennials are more tech savvy and are certainly more comfortable with new technology than people from earlier eras.
However, people buy people and sales are $80 \%$ emotion driven. We might like to think otherwise, but it's a fact that we all make our buying decisions based on an emotion. That means it is a really important factor for the team to understand, as well as how it impacts their ability to communicate at the level the patient (new or existing) needs - or even a colleague.

Repeated lockdowns pretty much removed personal interactions and, as we try to rekindle this in the workplace and in life in general, it's even more apparent that there is something missing. It leaves many wondering if they've got rusty or lost the skill to hold meaningful conversations at all!

The truth is, millennials are on the back foot on this one, as one-on-one conversations and written communication (without text speak!) have never really been the forte of this generation.

This highly tech-savvy generation leads the 


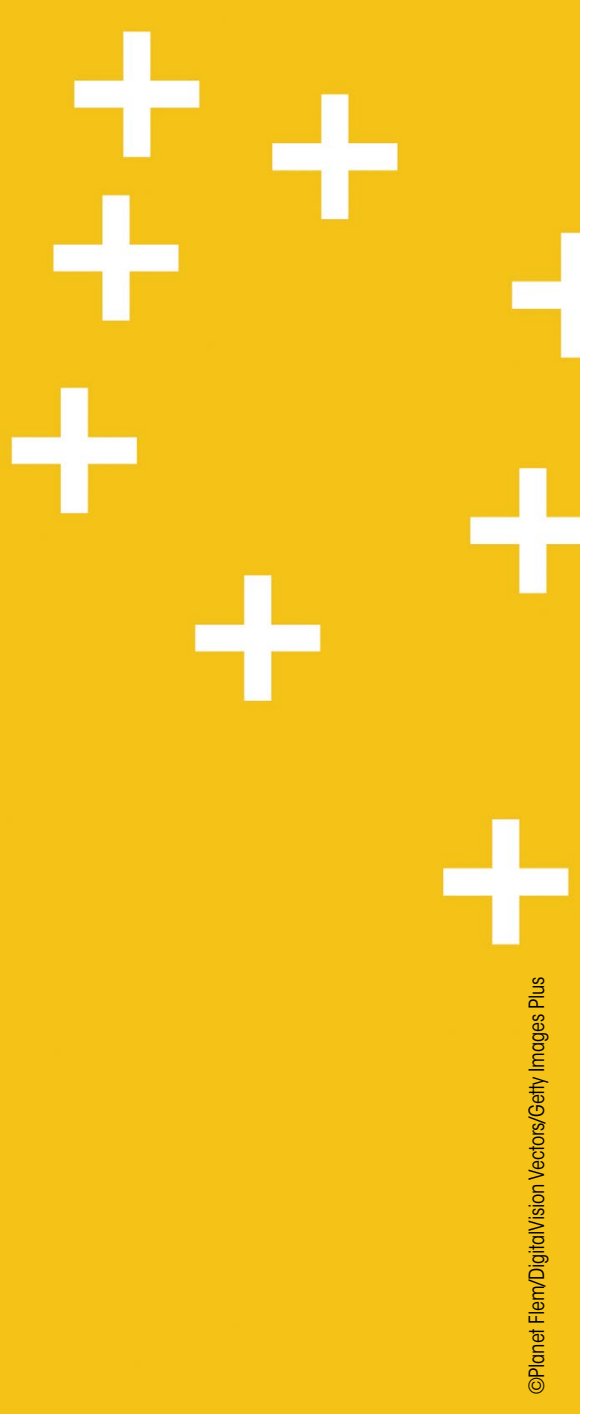

field when it comes to digital for both work and play, however, many of them have had so little exposure to real one-on-one style of conversation that they don't pick up on things that are obvious to others in the Gen X and Baby Boomer cohorts. That is important to remember.

In fact, several of my clients find having one receptionist who is a millennial and another a Gen X works best for them, as they have different strengths and learn from one another.

\section{Moving with the times}

This idea of learning from one another is crucial. Without getting too bogged down in science, it all comes down to your neural pathways. Think of them as an electrical impulse and, as you go to do something, these fire up, and they make the reaction you wanted possible. Hundreds of these die within us every day and they die because they are unused.

The good news is we can create new ones, better ones, different ones and you do this through repeating the action until those neural pathways are embedded and in place. Coaching and training taps directly into your neural pathways, it challenges your thinking, it creates new habits and better outcomes that, with practice, become embedded until they are second nature.

Think of coaching or training as the mental equivalent of a brain gym - you use it or lose it. For anyone to be at the top of their game, it's really important to keep pushing and stretching ourselves so we grow our mental capacity.

We do this by rewiring and creating new neural pathways through training, which will ultimately lead to improved performance, and a significant part of that is adjusting our mindset.

\section{'For anyone to be at the top of their game, it's really important to keep}

\section{pushing and stretching ourselves so we}

\section{grow our mental capacity.'}

\section{Beyond conventional wisdom}

Mindset has become a buzz word but, really, what does it mean?

We all have a rough idea but if you asked two people to tell you, I guarantee you would get very different answers.

As a coach, I know a lot about mindset: what it is, its importance, what it does for a team and how it enhances performance like nothing else.

Large corporates have successfully applied mindset training within their business development programmes for a while now, because they understand the massive impact it has on their profitability and their success - so who wouldn't want this in their dental practice?

It's a no-brainer and beats stressing about how to change the performance and profitability of your dental practice dramatically in one fell swoop.

\section{A step in the right direction}

Change is tough, I understand that, but I hope it is clear by now that positive changes need to be made by the dental team to achieve a healthier mindset.

I think if you randomly asked six practice owners if they considered themselves stuck in the past, they would probably all say no. It's often not until someone points it out to us that we stop to take notice of the reality of our situation.

It's a bit like the friend who says, 'I'm pleased you've thrown out that old coat, I
Then the real work can begin in helping the team develop a sense of self-worth and self-awareness around their colleagues and their patients.

\section{Seeking inspiration}

There are five known stages for building a team effectively - forming, storming, norming, performing, and adjourning.

Each of the five stages of team development represents a step on the teambuilding ladder but most don't ever emerge from stage two, where people start to push against the established boundaries. If no greater progress is made, they remain in a step that is known to create conflict or friction, which is clearly a terrible place to be stuck.

This is down to a lack of effective coaching, training and leadership that encourages growth and performance in its people. To help overcome this potential pitfall, there are many great motivational speakers and writers out there, and I would recommend Brené Brown and Steve Head to get the ball rolling. Both have books, TED Talks and other online content that are easily accessible.

Closer to home, why not book a strategy call with me to see how I can help your team members achieve the same great results as previous clients by embracing a healthier mindset? Simply email tracy.stuart@ nbstraining.co.uk or call 01438217944.

https://doi.org/10.1038/s41407-021-0615-y 